\title{
A Single Center Observational Study to Evaluate Epidemiology and Susceptibility Patterns to Antimicrobial Agents at a Tertiary Care Hospital in India
}

\author{
Pritam Jagansing Pardeshi*
}

Consultant Microbiologist, Bhatia Hospital, Mumbai, India

*Corresponding author

\begin{tabular}{|l|}
\hline K e y w o r d s \\
$\begin{array}{l}\text { Enterococcus faecium, } \\
\text { Staphylococcus aureus, } \\
\text { Klebsiella pneumoniae, } \\
\text { Acinetobacter baumannii }\end{array}$ \\
\hline Article Info \\
\hline $\begin{array}{l}\text { Accepted: } \\
\text { 26 July } 2018 \\
\text { Available Online: } \\
\text { 10 August } 2018\end{array}$ \\
\hline
\end{tabular}

\section{Introduction}

The unrestricted prescription of antibiotics by clinicians has led to an abrupt rise in anti- microbial resistance, threatening the use of major available drugs for the treatment of various infections (Zaman et al.,). Of particular concern in Asian sub-continent are 
the Gram-negative infections particularly caused by ESKAPE pathogens which include Enterococcus faecium, Staphylococcus aureus, Klebsiella pneumoniae, Acinetobacter baumannii, Pseudomonas aeruginosa anr Enterobacter cloacae (Zellweger et al., 2017). The primary mechanisms responsible for this resistance are the production of various classes of beta-lactamase enzymes including extended spectrum $\beta$-lactamases (ESBLs) and metallo $\beta$-lactamases (MBLs). ESBLs are $\beta$ lactamases capable of hydrolyzing various classes of antibiotics including pencillins, monobactams and other several groups of $\beta$ lactam antibiotics, notably third and fourth generation cephalosporins. MBLs are known as Carbapenem hydrolyzers (Rawat and Nair, 2010) (Munita and Arias, 2016). The majority of ESBL and MBL producing organisms produce more than one $\beta$-lactamase and thus show cross-resistance to other groups of antibiotics (Rawat and Nair, 2010). The prevalence of ESBL producers in India range from $28 \%-84 \%$ and $\mathrm{MBL}$ producers range from 7-71\% (Singh et al., 2015).

In addition to limiting the treatment options, the growing anti-microbial resistance is associated with a clinical and economic burden, including increased mortality, greater hospital and antibiotic costs, and longer stays in hospitals and intensive care units (Barriere, 2015). This is mainly attributed to improper empirical therapy in the beginning, causing dealy in effective therapy and poor treatment outcomes.

For choosing the right kind of treatment for the management of infections, various factors are considered including individual risk factors, clinical severity and most importantly local epidemiology. The anti-microbial resistance pattern of pathogens varies in different geographical locales and the knowledge of local epidemiology is helpful to choose the effective antibiotic for treating such pathogens. In the present study, we retrospectively analyzed the antibiotic susceptibility pattern of Gramnegative clinical isolates collected during the study period.

\section{Materials and Methods}

\section{Source of isolates}

This study was carried out in adult patients suffering from various bacterial infections and admitted to IPD or ICU for treatment from May 2017 to December 2017. The clinical samples used for pathogen isolation were wound, respiratory specimens, blood, fluids, tissue, bile, catheter tip, ear swabs and stools. The sample collection and processing were done as per standard microbiology laboratory operating procedures. Colony counts higher than or equal to $10^{5}$ colony forming units $(\mathrm{CFU}) / \mathrm{mL}$ were considered significant (Cheesbrough, 2005).

\section{Pathogen Isolation and identification}

The identification of clinical isolates was done on the basis of Gram-staining, colony morphology, motility and different biochemical reactions using standard techniques. Required clinical specimens were collected in sufficient amount aseptically which were then inoculated or streaked on different selective and non-selective culture media as per the standard microbiological procedures. Blood samples collected in brain heart infusion (BHI) broth were incubated aerobically overnight at $37^{\circ} \mathrm{C}$ followed by subculturing in the respective media (Cheesbrough, 2005).

\section{Antibiotic susceptibility testing}

In vitro susceptibility testing was done by Kirby-Bauer disk diffusion method for all the pathogen isolates as per Clinical Laboratory 
Standard Institute (CLSI) guidelines. Discs of CSE-1034, Meropenem, Piperacillin/ Tazobactam and Cefaperazone/ Sulbactam were used in the study.

The results were interpreted as per the interpretation criteria of the Clinical and Laboratory Standards Institute (CLSI) standards (Bauer and Kirby, 1966; CLSI, 2017).

CSE1034 is a novel antibiotic adjuvant entity of ceftriaxone and sulbactam $(2: 1 \mathrm{w} / \mathrm{w})$ along with non-antibiotic adjuvant disodium EDTA (ethylene diamine tetra aceticacid), which displays a broad spectrum of activity against a range of infections caused by Gram negative organisms. This new drug has been approved by Drug Controller General of India (DCGI) (Nazish Fatima, Mohammed Shameem et al., 2017).

CSE-1034, for which CLSI breakpoints are not available hence interpretative breakpoints provided by the manufacturer were used. Criteria for Enterobacteriaceae were $>23 \mathrm{~mm}$ Sensitive, 20-22-Intermediate, and $\leq 19$-Resistant and for other Gram-negative bacilli were $>21 \mathrm{~mm}$ - Sensitive, 14-20Intermediate, and $\leq 13$ - Resistant (Prabhu, Mohit Arora et al., 2017). Data entered in excel sheet and analysed.

This study was approved by Bhatia hospital, Medical Research Society.

\section{Results and Discussion}

\section{Sample collection and pathogen isolation}

A total of 241 (40.2\%) Gram-negative isolates obtained from 600 screened clinical specimens were included in this retrospective analysis. The major clinical samples processed for pathogen isolation were urine $(47.7 \%)$, wound swabs and respiratory specimens (19.1\% each) whereas all other specimens contributed $14.1 \%$ to the total pool. The samples processed least were bile, catheter tip, ear swabs, and stools. For other details, refer to Table 1. Higher number of isolates $(53.1 \%)$ was obtained from females.

\section{Microbiological characteristics}

The detailed profile of various organisms isolated is shown in Table 1. 41.5\% of the isolates were $E$. coli followed by, $K$. pneumoniae $(21.9 \%)$ and $P$. aeruginosa (15.4\%).

E. coli was predominant in both ICU and IPD followed by K. pneumoniae (Table 1).

The susceptibility profile to different antibiotics based on family type is shown in Table 2. Overall, $83.4 \%$ (201) were reported to be sensitive to CSE-1034, 63.9\% (154) to Meropenem, $49.4 \%$ (119) to Pip-Taz and $57.3 \%$ (128) to Cefaperazone-Sulbactam.

Overall, the susceptibility rates to all the antibiotics were higher in Enterobacteriaceae compared to Non-Enterobacteriaceae family.

The highest susceptibility among Enterobacteriaceae was shown to CSE-1034 (96.2\%) and least was shown towards Pip/Taz $(55.4 \%)$.

Among non-Enterobacteriaceae isolates also, the highest susceptibility was observed to Meropenem (45.6\%) whereas lowest was reported to Pip/Taz (29.8\%) (Table 2).

\section{Susceptibility results of Enterobacteriaceae based on phenotypic characterization}

As shown in Table 3 only two isolates of Enterobacteriaceae were reported as MBL producers. Both the isolates were reported CSE-1034-susceptible, one was Meropenem- 
susceptible and none was reported susceptible to Pip/Taz and Cefaperazone-Sulbactam.

It was also seen that the susceptible percentage of ESBL producing Enterobacteriaceae to CSE-1034 was $97.3 \%$ and Meropenem (86.5\%) which is significantly high compared to Pip-Taz $(54.1 \%)$ and Cefaperazone-Sulbactam $(64.9 \%)$.

44/184 (23.9\%) of Enterobacteriaceae isolates were ESBL+MBL producers.

The susceptible percentage of ESBL+MBL producing Enterobacteriaceae isolates to CSE1034 was $93.2 \%$. Only $4.5 \%$ isolates each were susceptible to Meropenem and Pip/Taz and $11.4 \%$ were susceptible to Cefaperazone/ Sulbactam.
Susceptibility results of NonEnterobacteriaceae based on phenotypic characterization

As shown in Table 3 none of the isolates from non-Enterobacteriaceae family were reported as only MBL producers.

$15.8 \%(9 / 57)$ of Non-Enterobacteriaceae isolates were identified as ESBL producers and $50.9 \%(29 / 57)$ were ESBL+MBL producers. The susceptibility rates of ESBL producing Enterobacteriaceae were CSE-1034 (66.7\%), Meropenem (55.6\%), Pip-Taz $(33.3 \%)$ and Cefaperazone-Sulbactam (33.3\%). The susceptibility rate of ESBL+MBL producing Enterobacteriaceae isolates to CSE-1034 was $48.3 \%$. Only $6.9 \%$ isolates were susceptible to Meropenem and none to Pip-Taz and $3.4 \%$ isolates was susceptible to Cefaperazone-Sulbactam.

Table.1 Demographic and baseline characteristics of all study subjects

\begin{tabular}{|c|c|c|c|c|}
\hline Characteristics & & Total $(n=241)$ & IPD $(n=168)$ & $\operatorname{ICU}(n=73)$ \\
\hline \multirow[t]{2}{*}{ Gender } & Male, n (\%) & $113(46.9)$ & 71 & 42 \\
\hline & Female, n (\%) & $128(53.1)$ & 97 & 31 \\
\hline Age (year) & Mean \pm SD & & $54.5 \pm 20.57$ & $52.5 \pm 39.66$ \\
\hline \multirow[t]{7}{*}{ Clinical sample } & Urine $(\%)$ & $115(47.7)$ & $88(52.4)$ & $27(36.9)$ \\
\hline & Wound (\%) & $46(19.1)$ & $37(22.0)$ & $9(12.3)$ \\
\hline & $\begin{array}{l}\text { Respiratory specimens } \\
\text { (\%) }\end{array}$ & $46(19.1)$ & $17(10.1)$ & $29(39.7)$ \\
\hline & Blood (\%) & $12(4.9)$ & $9(5.4)$ & $3(4.1)$ \\
\hline & Fluids (\%) & $6(2.5)$ & $4(2.4)$ & $2(2.7)$ \\
\hline & Tissue samples (\%) & $6(2.5)$ & $5(2.9)$ & $1(1.4)$ \\
\hline & $*$ Others $(\%)$ & $10(4.1)$ & $8(4.8)$ & $2(2.7)$ \\
\hline \multicolumn{5}{|c|}{ Pathogen $(n=241)$} \\
\hline \multicolumn{5}{|c|}{ Enterobacteriaceae $(n=184)$} \\
\hline & E. $\operatorname{coli}(\%)$ & $100(41.5)$ & $72(42.9)$ & $28(38.3)$ \\
\hline & K. pneumonia $(\%)$ & $53(21.9)$ & $33(19.6)$ & $20(27.4)$ \\
\hline & E. cloacacae $(\%)$ & $10(4.1)$ & $8(4.8)$ & $2(2.7)$ \\
\hline & ${ }^{* *}$ Others $(\%)$ & $21(8.7)$ & $18(10.7)$ & $3(4.1)$ \\
\hline \multicolumn{5}{|c|}{ Non-Enterobacteriaceae $(n=57)$} \\
\hline & P. aeruginosa $(\%)$ & $37(15.4)$ & $26(15.5)$ & $11(15)$ \\
\hline & Acinetobacter spp. (\%) & $16(6.6)$ & $9(5.4)$ & $7(9.6)$ \\
\hline & ${ }^{* * *}$ Others $(\%)$ & $4(1.7)$ & $2(1.2)$ & $2(2.7)$ \\
\hline
\end{tabular}

*Others include bile, catheter tip, ear swabs, stool samples

** Others include C. koseri, E. aerogenes, S. typhii, M. morgannii, Proteus spp., Providencia spp., S. marcescens

*** Others include A. hydrophila, B. cepaceae, Streptomonas spp. 
Table.2 In vitro Susceptibility profile of various antibiotics tested

\begin{tabular}{|c|c|c|c|c|c|c|}
\hline \multirow[t]{2}{*}{ Antibiotic } & \multicolumn{2}{|c|}{$\begin{array}{l}\text { Enterobacteriaceae } \\
\qquad(\mathrm{n}=184)\end{array}$} & \multicolumn{2}{|c|}{$\begin{array}{c}\text { Non- } \\
\text { Enterobacteriaceae } \\
(\mathbf{n}=\mathbf{5 7})\end{array}$} & \multicolumn{2}{|c|}{$\begin{array}{l}\text { Overall susceptibility } \\
\qquad(\mathrm{n}=\mathbf{2 4 1})\end{array}$} \\
\hline & Sensitive & Resistant & Sensitive & Resistant & Sensitive & Resistant \\
\hline CSE-1034 & $177(96.2 \%)$ & $7(3.8 \%)$ & $24(42.1 \%)$ & $33(57.9 \%)$ & $201(83.4 \%)$ & $40(16.6 \%)$ \\
\hline Meropenem & $128(69.6 \%)$ & $54(29.3 \%)$ & $26(45.6 \%)$ & $30(52.6 \%)$ & $154(63.9 \%)$ & $87(36.1 \%)$ \\
\hline Pip/Taz & $102(55.4 \%)$ & $82(44.6 \%)$ & $17(29.8 \%)$ & $40(70.2 \%)$ & $119(49.4 \%)$ & $122(50.6 \%)$ \\
\hline $\begin{array}{l}\text { Cefaperazone- } \\
\text { Sulbactam }\end{array}$ & $117(63.6 \%)$ & $66(35.9 \%)$ & $21(36.8 \%)$ & $36(63.2 \%)$ & $138(57.3 \%)$ & $103(42.7 \%)$ \\
\hline
\end{tabular}

Note: Isolates with Intermediate susceptibility have been considered as resistant

Table.3 In vitro Susceptibility profile of various antibiotics tested based on different phenotypes

\begin{tabular}{|c|c|c|c|c|c|c|}
\hline $\begin{array}{c}\text { Phenotypic } \\
\text { characteriz } \\
\text { ation }\end{array}$ & Location & Family & $\begin{array}{l}\text { CSE-1034 } \\
\mathbf{N}(\%)\end{array}$ & $\begin{array}{c}\text { Meropene } \\
\text { m } \\
\mathbf{N}(\%)\end{array}$ & $\begin{array}{l}\text { Pip/Taz } \\
\text { N }(\%)\end{array}$ & $\begin{array}{c}\text { Cefaperazon } \\
\text { e-Sulbactam } \\
\mathbf{N}(\%)\end{array}$ \\
\hline \multirow{3}{*}{$\begin{array}{l}\text { MBLs } \\
(n=2) \\
(0.8 \%)\end{array}$} & $\begin{array}{l}\text { IPD/ICU } \\
(2 / 0)\end{array}$ & $\begin{array}{l}\text { Enterobacteriaceae } \\
(\mathrm{n}=2)\end{array}$ & $2(100)$ & $1(50)$ & 0 & 0 \\
\hline & $\begin{array}{l}\text { IPD/ICU } \\
(0 / 0)\end{array}$ & $\begin{array}{l}\text { Non-Enterobacteriaceae } \\
(\mathrm{n}=0)\end{array}$ & 0 & 0 & 0 & 0 \\
\hline & & Total $(n=2)$ & $2(100)$ & $1(50)$ & 0 & 0 \\
\hline \multirow{3}{*}{$\begin{array}{l}\text { ESBLs } \\
(\mathrm{n}=\mathbf{8 3}) \\
(\mathbf{3 4 . 4 \% )}\end{array}$} & $\begin{array}{l}\text { IPD/ICU } \\
(56 / 18)\end{array}$ & $\begin{array}{l}\text { Enterobacteriaceae } \\
(\mathrm{n}=74)\end{array}$ & 72 (97.3) & $64(86.5)$ & $40(54.1)$ & 48 (64.9) \\
\hline & $\begin{array}{l}\text { IPD/ICU } \\
(6 / 3)\end{array}$ & $\begin{array}{l}\text { Non-Enterobacteriaceae } \\
(\mathrm{n}=9)\end{array}$ & $6(66.7)$ & $5(55.6)$ & $3(33.3)$ & $3(33.3)$ \\
\hline & & Total $(n=83)$ & 78 (93.9) & $69(83.1)$ & $43(51.8)$ & $51(61.4)$ \\
\hline \multirow{3}{*}{$\begin{array}{l}\text { ESBLs+ } \\
\text { MBLs } \\
(\mathrm{n}=73) \\
(30.3 \%)\end{array}$} & $\begin{array}{l}\text { IPD/ICU } \\
(25 / 19)\end{array}$ & $\begin{array}{l}\text { Enterobacteriaceae } \\
(\mathrm{n}=44)\end{array}$ & $41(93.2)$ & $2(4.5)$ & $2(4.5)$ & $5(11.4)$ \\
\hline & $\begin{array}{l}\text { IPD/ICU } \\
(18 / 11)\end{array}$ & $\begin{array}{l}\text { Non-Enterobacteriaceae } \\
(\mathrm{n}=29)\end{array}$ & $14(48.3)$ & $2(6.9)$ & 0 & $1(3.4)$ \\
\hline & & Total $(n=73)$ & $55(75.2 \%)$ & $4(5.5)$ & $2(2.7)$ & $6(8.2)$ \\
\hline
\end{tabular}

Multidrug-resistance (MDR) has been identified as an increasing health problem and poses a major challenge for patient management and public health around the globe. Though, various guidelines are available for the management of bacterial infections, adoption of these guidelines at the hospital level is challenged by the varied MDR resistance trends in different geographical locales. Thus, anti-microbial surveillance studies to monitor the MDR are important to help clinicians choose a right empirical therapy. The current study provides insights in the antibiogram of commonly used drugs in a tertiary care hospital in India.

In this study, overall half of isolates were reported from urine samples followed by respiratory and wound specimens. Further data analysis based on specimens from IPD/ICU has shown that isolates were predominantly obtained from urine in IPD 
followed by wound whereas in ICU patients, the predominant specimens were urine and respiratory. The distribution pattern of pathogens was almost similar in IPD and in ICU, with $K$. pnuemoniae and Acinetobacter spp. numerically on the higher side in ICU patients. Mechanical ventilation and the common use of catheters in ICU patients could be one of the reasons for this uneven distribution of clinical specimens in the two populations. Our study results are concordant to other studies. Venkataraman et al., (Venkataraman et al., 2018) in their multicenter study on ICU patients $\geq 48 \mathrm{~h}$, reported Ventilator Associated Pneumonia (VAP) followed by Catheter Associated Urinary Tract Infection (CAUTI) as the most common infections with Acinetobacter being the most common isolate in VAP patients and Klebsiella in CAUTI. Similarly, Rosental et al., (Rosenthal et al., 2006) have reported that ventilator-associated pneumonia posed the greatest risk ( $41 \%$ of all device-associated infections) followed by bloodstream infections (BSIs) (30\%) and catheterassociated urinary tract infections (29\%) in a study based on device-associated nosocomial infections in 55 ICUs of 8 developing countries, including India. In another study based on ICUs as part of the international infection control consortium from seven Indian cities, it was reported that the overall infection rates were $10.46 / 1000$ ventilator days for VAP, 7.92/1000 catheter days for CLABSI, and 1.41/1000 catheter days for CAUTI (Mehta et al., 2007)

In our study $65.6 \%$ of the isolates were reported to be beta-lactamase producers with $34.4 \%$ as ESBL producers, $0.8 \%$ as MBL producers and $30.3 \%$ as ESBL+MBL producers. This could be attributed to the fact that patients included in our study must have already been exposed to hospital environment and received some empiric antibiotics at the time of enrollment making them a higher risk for developing multidrug resistance. Compared to IPD (62.5\%), the beta-lactamase producers were more in ICU patients $(69.9 \%)$. Moreover, $41.1 \%$ were $\mathrm{MBL}+\mathrm{ESBL}$ producers in ICU patients compared to $25.6 \%$ among IPD patients, whereas ESBL producers were more in IPD patients $(28.7 \%$ vs. $36.9 \%$ ) (Table 3 ).

In our hospital, the highest susceptibility of ESBL isolates was reported towards CSE1034 (93.9\%) followed by Meropenem $(83.1 \%)$. Pip-Taz susceptibility rate was $51.8 \%$ and Cefaperazone-Sulbactam was $61.4 \%$. The AMR surveillance study conducted in India has shown resistance against Pip-Taz has risen to 65-70\% (Kumar et al., 2013).

Meropenem is being used for severe nosocomial infections, often in hospital units. Their value lies in their broad spectrum of action and in overcoming resistance in Gramnegative bacilli. Exposure and use of carbapenems for the treatment of diverse infectious diseases has appeared to be a main reason for the development of resistance (Kumar et al., 2013). The emergence of carbapenem resistance among clinical isolates has raised fears that effective antimicrobial treatment options for these isolates may soon be severely limited (Ogutlu et al., 2014). The low rate of carbapenem susceptibility reported among ESBLs in this surveillance study needs to be addressed. This pattern of resistance clearly indicates that other mechanisms of resistance to Carbapenems are increasing among ESBLs including efflux pump, membrane impermeability, etc. The emergence of ESBL/MBL producing isolates which is $30 \%$ in this study is also a matter of big concern as carbapenems are considered as the last resort drugs for serious bacterial infections. A significantly higher incidence of carbapenem-resistant Gram-negative bacteria has also been reported by Ghosh et 
al., (Ghosh et al., 2012) from AIIMS, Delhi. Similarly, Singh et al., (Singh et al., 2015) have reported that $15-22 \%$ of the gramnegative isolates were MBLs in their study.

Interestingly, a significant number of both ESBL and MBL-ESBL isolates were sensitive to CSE-1034. The high sensitivity of gramnegative pathogens to CSE-1034 has been reported in several other studies too (Chaudhary and Payasi, 2013a) (Chaudhary et al., 2018) (Chaudhary et al., 2017). In an antimicrobial susceptibility pattern study conducted by Sahu et al., 100\%, 64\% and $63 \%$ of ESBL producing $A$. baumannii, $K$. pneumoniae and $E$. coli were reported to be susceptible to CSE-1034 [19]. In the same study, $89 \%, 60 \%, 42 \%$ and $41 \%$ of MBL producing isolates of $A$. baumannii, E. coli, $P$. aeruginosa and $K$. pneumoniae, respectively were susceptible to CSE-1034 (Sahu et al., 2014). In another anti-microbial susceptibility pattern study, $67-81 \%$ of ESBL producing $K$. pneumoniae isolates were reported to be highly susceptible to CSE-1034. Similarly, a study on antibiotic susceptibility pattern of various gram-negative pathogens isolated from ICU patients had reported that CSE1034 has higher clinical efficacy compared to carbapenems (Chaudhary and Payasi, 2013b).These observations assume a huge importance in the backdrop of prescribing empirical therapy for MDR bacterial infections particularly caused by MBL producing isolates. As CSE-1034, a betalactam/beta-lactamase combination along with "EDTA" has a good susceptibility profile against all the Gram-negative pathogens tested, it can serve as an effective alternative to reduce the selection pressure on carbapenem-resistant strains through carbapenem over-use.

In conclusion, our analysis suggests that pathogens isolated from various clinical sources demonstrated resistance to a variety of antimicrobials in our hospital. The high rate of antimicrobial resistance could be possibly explained by antibiotic misuse by public, inappropriate prescription by unskilled practitioners and laypersons, insufficient surveillance studies, poor drug quality and unhygienic conditions accounting for the spread of resistant bacteria. Moreover, CSE1034 remains the most effective drug against both ESBL and MBL producing gramnegative isolates. The high resistance observed in this study warrants the need for surveillance of resistance pattern of antimicrobial agents administered to patients undergoing treatment for better patient management. A careful monitoring of antimicrobial use, in hospital, is required to identify the situations in which prescription patterns are contributing to the development of resistance.

\section{Acknowledgements}

I am very thankful to Bhatia hospital, Microbiology department and Bhatia hospital Medical Research Society for allowing me to conduct the study.

\section{References}

Barriere, S.L. (2015). Clinical, economic and societal impact of antibiotic resistance. Expert Opin. Pharmacother. 16, 151153.

Bauer AW, Kirby WMM, Sherris JC, Turck M. Antibiotic susceptibility testing by standard single disc method. Am J Clin Pathol 1966; 45: 493-496.

Chaudhary, M., and Payasi, A. (2013a). Rising Antimicrobial Resistance of Pseudomonas aeruginosa Isolated from Clinical Specimens in India. J. Proteomics Bioinform. 6.

Chaudhary, M., and Payasi, A. (2013b).Incidence, prevalence and control of multidrug resistant (MDR) 
carbapenemase producing Acinetobacter baumanii in Indian intensive care units. J. Pharm. Res. 7, 175-180.

Chaudhary, M., Mir, M.A., and Ayub, S.G. (2017). Safety and efficacy of a novel drug elores (ceftriaxone + sulbactam + disodium edetate) in the management of multi-drug resistant bacterial infections in tertiary care centers: a post-marketing surveillance study. Braz. J. Infect. Dis. 21, 408-417.

Chaudhary, M., Ayub, S.G., and Mir, M.A. (2018). Comparative efficacy and safety analysis of CSE-1034: An open labeled phase III study in community acquired pneumonia. J. Infect. Public Health $O$.

Cheesbrough, M. (2005). District Laboratory Practice in Tropical Countries Part 1, second edition. Cambridge University Press, Cambridge UK, 105 - 115.

Clinical and Laboratory Standards Institute. Performance standards for antimicrobial susceptibility testing; 27th informational supplement. Wayne, PA: Clinical and Laboratory Standards Institute; 2017.

Ghosh, I., Raina, V., Kumar, L., Sharma, A., Bakhshi, S., Thulkar, S., and Kapil, A. (2012). Profile of infections and outcome in high-risk febrile neutropenia: experience from a tertiary care cancer center in India. Med. Oncol. Northwood Lond. Engl. 29, 1354-1360.

Kumar, S.G., Adithan, C., Harish, B.N., Sujatha, S., Roy, G., and Malini, A. (2013). Antimicrobial resistance in India: A review. J. Nat. Sci. Biol. Med. 4, 286-291.

Mehta, A., Rosenthal, V.D., Mehta, Y., Chakravarthy, M., Todi, S.K., Sen, N., Sahu, S., Gopinath, R., Rodrigues, C., Kapoor, P., et al., (2007). Deviceassociated nosocomial infection rates in intensive care units of seven Indian cities. Findings of the International
Nosocomial Infection Control Consortium (INICC). J. Hosp. Infect. 67, 168-174.

Munita, J.M., and Arias, C.A. (2016).Mechanisms of Antibiotic Resistance.Microbiol.Spectr.4.

Nazish Fatima1, Mohammed Shameem et al., Determination of susceptibility breakpoints of a novel Antibiotic Adjuvant Entity CSE1034 in extended spectrum-beta lactamases and metallo beta-lactamases producing resistant Enterobacteriaceae. Journal of Microbiology and Antimicrobial Agents. 2017; 3 (1): 25-33

Ogutlu, A., Guclu, E., Karabay, O., Utku, A.C., Tuna, N., and Yahyaoglu, M. (2014).Effects of Carbapenem consumption on the prevalence of Acinetobacter infection in intensive care unit patients. Ann. Clin. Microbiol. Antimicrob. 13, 7 .

Prabhu1, Mohit Arora et al., Determination of Susceptibility Breakpoints of Elores in Extended Spectrum Beta-lactamases and Metallo Beta-lactamases Producing Acinetobacter Species. International Journal of Contemporary Medical Research, 4(2): February 2017

Rawat, D., and Nair, D. (2010).Extendedspectrum $\beta$-lactamases in Gram Negative Bacteria. J. Glob. Infect. Dis. 2, 263-274.

Rosenthal, V.D., Maki, D.G., Salomao, R., Moreno, C.A., Mehta, Y., Higuera, F., Cuellar, L.E., Arikan, O.A., Abouqal, R., Leblebicioglu, H., et al., (2006). Device-associated nosocomial infections in 55 intensive care units of 8 developing countries. Ann. Intern. Med. 145, 582-591.

Sahu, M., Sanjith, S., Bhalekar, P., and Keny, D. (2014). Waging War Against Extended Spectrum Beta Lactamase and Metallobetalactamase Producing Pathogens- Novel Adjuvant 
Antimicrobial Agent Cse1034- An Extended Hope. J. Clin. Diagn.Res. JCDR 8, DC20-DC23.

Singh, A.K., Jain, S., Kumar, D., Singh, R.P., and Bhatt, H. (2015). Antimicrobial susceptibility pattern of extendedspectrum beta- lactamase producing Klebsiella pneumoniae clinical isolates in an Indian tertiary hospital. J. Res. Pharm. Pract. 4, 153-159.

Venkataraman, R., Divatia, J.V., Ramakrishnan, N., Chawla, R., Amin, P., Gopal, P., Chaudhry, D., Zirpe, K., and Abraham, B. (2018). Multicenter observational study to evaluate epidemiology and resistance patterns of common intensive care unit-infections. Indian J. Crit. Care Med. 22, 20.

Zaman, S.B., Hussain, M.A., Nye, R., Mehta, V., Mamun, K.T., and Hossain, N. A Review on Antibiotic Resistance: Alarm Bells are Ringing. Cureus9.

Zellweger, R.M., Carrique-Mas, J., Limmathurotsakul, D., Day, N.P.J., Thwaites, G.E., Baker, S., Ashley, E., de Balogh, K., Baird, K., Basnyat, B., et al., (2017). A current perspective on antimicrobial resistance in Southeast Asia. J. Antimicrob. Chemother. 72, 2963-2972.

\section{How to cite this article:}

Pritam Jagansing Pardeshi. 2018. A Single Center Observational Study to Evaluate Epidemiology and Susceptibility Patterns to Antimicrobial Agents at a Tertiary Care Hospital in India. Int.J.Curr.Microbiol.App.Sci. 7(08): 4340-4348.

doi: https://doi.org/10.20546/ijcmas.2018.708.455 